\title{
DAMPs from cell death to new life
}

\author{
Emilie Vénéreau ${ }^{1,2}$, Chiara Ceriotti ${ }^{1}$ and Marco Emilio Bianchi ${ }^{1,3 *}$ \\ ${ }^{1}$ Chromatin Dynamics Unit, Division of Genetics and Cell Biology, San Raffaele Scientific Institute, Milan, Italy, ${ }^{2}$ HMGBiotech \\ Srl, Milan, Italy, ${ }^{3}$ Università Vita-Salute San Raffaele, Milan, Italy
}

\section{OPEN ACCESS}

Edited by:

Abhishek D. Garg,

KU Leuven-University of Leuven,

Belgium

Reviewed by:

Graham Robert Leggatt,

University of Queensland, Australia Walter G. Land

University of Strasbourg, France

*Correspondence:

Marco Emilio Bianchi,

Chromatin Dynamics Unit, Division of

Genetics and Cell Biology,

San Raffaele Scientific Institute,

San Raffaele University, Via Olgettina

58, Milan 20133, Italy

bianchi.marco@hsr.it

Specialty section:

This article was submitted to Tumor

Immunity, a section of the

journal Frontiers in Immunology

Received: 01 July 2015

Accepted: 02 August 2015

Published: 18 August 2015

Citation:

Vénéreau E, Ceriotti C and Bianchi ME (2015) DAMPs from cell death to new life.

Front. Immunol. 6:422. doi: 10.3389/fimmu.2015.00422
Our body handles tissue damage by activating the immune system in response to intracellular molecules released by injured tissues [damage-associated molecular patterns (DAMPs)], in a similar way as it detects molecular motifs conserved in pathogens (pathogen-associated molecular patterns). DAMPs are molecules that have a physiological role inside the cell, but acquire additional functions when they are exposed to the extracellular environment: they alert the body about danger, stimulate an inflammatory response, and finally promote the regeneration process. Beside their passive release by dead cells, some DAMPs can be secreted or exposed by living cells undergoing a life-threatening stress. DAMPs have been linked to inflammation and related disorders: hence, inhibition of DAMP-mediated inflammatory responses is a promising strategy to improve the clinical management of infection- and injury-elicited inflammatory diseases. However, it is important to consider that DAMPs are not only danger signals but also central players in tissue repair. Indeed, some DAMPs have been studied for their role in tissue healing after sterile or infection-associated inflammation. This review is focused on two exemplary DAMPs, HMGB1 and adenosine triphosphate, and their contribution to both inflammation and tissue repair.

Keywords: DAMP, tissue repair, HMGB1, ATP, inflammation

\section{Introduction}

Our body evolved mechanisms to detect pathogens through the recognition of conserved molecular motifs, called pathogen-associated molecular patterns (PAMPs). The binding of these molecules to pattern recognition receptors (PRR), such as Toll-like receptors (TLR), triggers the response of the immune system against the intruder (1). However, this "Stranger Theory" could not explain why strong immune responses are elicited in sterile conditions such as ischemic injuries, trauma, tumors, tissue transplants, and autoimmune diseases. By symmetry to the PAMP concept, Polly Matzinger proposed the "Danger Theory" in which the injured tissues were postulated to release intracellular molecules [damage-associated molecular patterns (DAMPs)] that activate the immune system (2). This concept has roots in a clinical trial on kidney transplantation, in which the oxygen free radical scavenger superoxide dismutase was exploited to avoid reperfusion injury (3). However, for many years the "Danger Theory" remained a theoretical model, until High Mobility Group Box 1 (HMGB1) and uric acid crystals were recognized as DAMPs $(4,5)$. Since then, many more DAMPs were identified and their roles in health and disease are now partially understood (Table 1).

Damage-associated molecular patterns are molecules that have a physiological "day-time job" inside the cell, and have the additional job of signaling cell damage when they are outside the cell. Location, inside vs. outside the cells, is critical: DAMPs are invisible to the immune system when performing their day-time job, and become visible only when exposed to the extracellular environment.

Timing is also important. Initially, DAMPs were expected to attest cell death, and therefore to be released passively from dead cells. Indeed, HMGB1 was identified as a DAMP because it is 
TABLE 1 | List of putative DAMPs and role in inflammation and tissue repair.

\begin{tabular}{|c|c|c|c|c|c|c|}
\hline & DAMPs & Receptors & Release & Role in inflammation/immunity & Role in tissue repair & Reference \\
\hline \multirow[t]{5}{*}{ Nucleus } & Histones & $\begin{array}{l}\text { TLR2, TLR4 and } \\
\text { TLR9 }\end{array}$ & $\mathrm{P}, \mathrm{S}$ and $\mathrm{A}$ & $\begin{array}{l}\text { TLR- and inflammasome-dependent } \\
\text { inflammatory response }\end{array}$ & N.D. & (6) \\
\hline & $\begin{array}{l}\text { Genomic } \\
\text { DNA }\end{array}$ & TLR9 & $\mathrm{P}$ & $\begin{array}{l}\text { TLR9- and NALP3-mediated innate immune } \\
\text { response, DC maturation }\end{array}$ & N.D. & (6) \\
\hline & HMGB1 & $\begin{array}{l}\text { TLR2, TLR4, } \\
\text { RAGE and TIM3 }\end{array}$ & $P$ and $A$ & Recruitment/activation of immune cells & $\begin{array}{l}\text { Migration/proliferation of stem cells, } \\
\text { pro-angiogenic mediator. }\end{array}$ & (7) \\
\hline & IL1a & $\mathrm{IL}-1 \mathrm{R}$ & $\mathrm{P}$ & Strong pro-inflammatory activity & $\begin{array}{l}\text { Protective during early phase of } \\
\text { inflammation }\end{array}$ & $(7)$ \\
\hline & IL33 & ST2 & $P$ & $\begin{array}{l}\text { Secretion of pro-inflammatory and Th2 } \\
\text { cytokines }\end{array}$ & $\begin{array}{l}\text { Epithelial cells proliferation and mucus } \\
\text { production in the gut }\end{array}$ & (8) \\
\hline \multirow[t]{6}{*}{ Cytosol } & ATP & $\mathrm{P} 2 \mathrm{Y} 2$ and $\mathrm{P} 2 \mathrm{X} 7$ & $P$ and $A$ & $\begin{array}{l}\text { Macrophages recruitment, IL-1 } 1 \beta \text { production } \\
\text { by DC, antitumor immunity }\end{array}$ & $\begin{array}{l}\text { Migration/proliferation of epithelial and } \\
\text { endothelial cells, pro-angiogenic role }\end{array}$ & (9) \\
\hline & F-actin & DNGR1 & $P$ & $\begin{array}{l}\text { Contribution in recognition of necrotic cells } \\
\text { by DC }\end{array}$ & N.D. & $(10)$ \\
\hline & Cyclophilin A & CD147 & A & $\begin{array}{l}\text { Inflammatory cells recruitment, inflammatory } \\
\text { mediators release }\end{array}$ & N.D. & $(10)$ \\
\hline & HSPS & $\begin{array}{l}\text { CD91, TLR2, } \\
\text { TLR4, SREC1 } \\
\text { and FEEL1 }\end{array}$ & $\mathrm{P}, \mathrm{S}$ and $\mathrm{A}$ & $\begin{array}{l}\text { Recruitment of immune cells DC maturation, } \\
\text { T cell-based antitumor immunity }\end{array}$ & $\begin{array}{l}\text { Wound debris clearance, cell } \\
\text { migration/proliferation and collagen } \\
\text { synthesis in skin }\end{array}$ & $(7)$ \\
\hline & $\begin{array}{l}\text { Uric acid } \\
\text { crystals }\end{array}$ & NLRP3 & $\mathrm{P}$ & DC maturation and neutrophil recruitment & N.D. & $(7)$ \\
\hline & S100s & $\begin{array}{l}\text { TLR2, TLR4, } \\
\text { RAGE }\end{array}$ & $P$ & $\begin{array}{l}\text { Potent immunostimulatory activity, } \\
\text { monocytes and neutrophils recruitment }\end{array}$ & Myoblast proliferation/differentiation & $(7)$ \\
\hline \multirow[t]{2}{*}{ Mitochondria } & $\begin{array}{l}\text { Mitochondrial } \\
\text { DNA }\end{array}$ & TLR9 & $\mathrm{P}$ & Macrophages and neutrophils activation & N.D. & $(11)$ \\
\hline & $\begin{array}{l}\text { Mitochondrial } \\
\text { trascription } \\
\text { factor } \mathrm{A}\end{array}$ & RAGE and TLR9 & $\mathrm{P}$ & DC activation, type I interferon release & N.D. & $(11)$ \\
\hline ER & Calreticulin & CD91 & $P$ and $S$ & $\begin{array}{l}\text { Potent "eat me" signal, mediator of tumor } \\
\text { immunogenicity }\end{array}$ & $\begin{array}{l}\text { Cell migration/proliferation, } \\
\text { extracellular matrix production }\end{array}$ & $(10)$ \\
\hline
\end{tabular}

P, passive release; $A$, active secretion; S, surface exposure; ER, endoplasmic reticulum; N.D. not described.

passively released by necrotic cells, which undergo an untimely death, but not by apoptotic cells, which eliminate themselves in an elaborately programed way (4). However, an important addition to the DAMP concept is that DAMPs do not necessarily originate from dead cells: DAMPs can be secreted or exposed by living cells undergoing a life-threatening stress. Indeed, alerting the immune system as soon as possible can bring advantages. HMGB1 can be secreted by stressed cells via a private secretion pathway, not involving the endoplasmic reticulum $(12,13)$. Adenosine triphosphate (ATP) can be actively released via vesicles and connexin or pannexin hemichannels (14). Other DAMPs, such as calreticulin and heat shock protein 90 (HSP90), are exposed de novo or become enriched on the outer leaflet of the plasma membrane (15).

It is now time to recognize another essential feature of DAMPs: they are essential for tissue healing after inflammation, both sterile and infection-associated. This review will focus on two exemplary DAMPs, HMGB1 and ATP, and their contribution to both inflammation and tissue repair.

\section{HMGB1 and ATP as Exemplary DAMPs}

\section{HMGB1, a Redox-Sensitive DAMP}

HMGB1 is a mobile chromatin protein that acts as a DNA chaperone, by binding DNA transiently and bending it reversibly. As a DNA chaperone, it facilitates nucleosome formation, contributes to the binding of proteins, including transcription factors that distort DNA upon binding, and participates in transcription, replication, and DNA repair (16). HMGB1 is constitutively expressed in almost all cell types, and to act as a DAMP it must relocate into the external environment: it is passively released following traumatic cell death (but not apoptosis) and is secreted during severe stress $(4,17)$.

HMGB1 secretion is not completely understood. Drawing a comparison with another leaderless protein, IL-1 $\beta$, a "two-step model" for HMGB1 secretion was proposed, which involves a first trigger to induce HMGB1 acetylation and cytoplasmic translocation and a second trigger to elicit its extracellular transport (18) Indeed, secreted HMGB1 (as opposed to HMGB1 passively released by dead cells) is hyperacetylated (19). In accordance with the two-step model, Lu et al. (20) have demonstrated that the inflammasome, in particular NLRP3, is involved in the release of HMGB1. Inflammasomes are large caspase-1-activating complexes, composed by the assembly of proteins that are ultimately activated by both PAMPs and DAMPs (21). There are multiple inflammasome complexes, and among them the one containing NLRP3 (also known as NALP3 and cryopyrin) is the most studied. Since the synthesis of NLRP3 is triggered by TLR signaling, it has recently been proposed that HMGB1 itself could "prime" the inflammasome through its binding to TLR2/TLR4 (22). Indeed, the role of HMGB1 in inflammasome activation has been demonstrated in a model of heatstroke-induced liver injury (23). 
Once in the extracellular milieu, HMGB1 signals danger to the surrounding cells, triggers inflammation, and activates innate and adaptive immunity by interacting with multiple receptors (24).

The first receptor described for HMGB1 is the receptor for advanced glycation endproducts (RAGE), a multifunctional transmembrane protein of the immunoglobulin superfamily (25). Under physiological conditions, RAGE is expressed at low levels in the majority of tissues and, interestingly, at high levels in the lung. In pathophysiological conditions such as chronic inflammation, RAGE expression is considerably increased in different tissues, in particular activated endothelium and leukocytes (26). HMGB1 signaling through RAGE leads to activation of the nuclear factor- $\mathrm{KB}(\mathrm{NF}-\kappa \mathrm{B})$ pathway, as well as to signal transduction through JNK, and p38 (27). In addition, HMGB1/ RAGE interactions lead to the activation of the ERK MAP kinase pathway, which is important in cell migration, tumor proliferation and invasion, and expression of matrix metalloproteinases. The HMGB1/RAGE axis is mainly involved in the recruitment and migration of cells, directly by inducing expression of adhesion molecules, such as VCAM-1 and ICAM-1 (28), or indirectly by inducing secretion of chemokines, in particular CXCL12, which in turn forms a heterocomplex with HMGB1 (29).

HMGB1 also binds to TLRs. In complex with CpG-ODNs, HMGB1 binds to TLR9 and enhances cytokine production in plasmacytoid dendritic cells (DCs) (30). When HMGB1 is bound to nucleosomes, it activates macrophages and DCs through TLR2 (31). However, most studies focused on the HMGB1/TLR4 axis. TLR4 mediates cell responses to lipopolysaccharide (LPS), but responds to several DAMPs as well. The contribution of the HMGB1/TLR4 axis to inflammation and immune regulation has been demonstrated in a wide range of experimental models, such as liver and lung damage, cancer, and epilepsy (32-35). Recently, a large body of evidence demonstrated that the redox state of cysteines modulates the binding of HMGB1 to its receptors, and consequently its activities.

HMGB1 contains three cysteines: C23 and C45 can form a disulfide bond, and C106 is unpaired. These cysteines are modified by redox reactions, giving rise to three isoforms named "fully reduced HMGB1" for the all-thiol form, "disulfide HMGB1" for the partially oxidized one, and "sulfonyl HMGB1" for the terminally oxidized form (36). Fully reduced HMGB1 forms a heterocomplex with the chemokine CXCL12, which binds with increased affinity to its CXCR4 receptor (29). Conversely, the extracellular TLR4 adaptor myeloid differentiation factor 2 (MD-2) binds specifically to disulfide HMGB1, and not to the other redox forms, triggering the expression of chemokines and cytokines (37). Notably, interaction with MD-2 also requires the third cysteine, in the fully reduced form. Thus, the disulfide bond between $\mathrm{C} 23$ and C45 makes HMGB1 a proinflammatory cytokine, whereas further cysteine oxidation to sulfonates abrogates both the chemoattractant and proinflammatory activities of HMGB1 (38). Several studies demonstrated a correlation between the presence of the disulfide HMGB1 and the onset of pathologies such as brain injury, liver damage, myositis, and juvenile idiopathic arthritis (19, 39-41). Moreover, disulfide HMGB1, and not the reduced form, contributes to nociceptive signal transmission via activation of TLR4 (42) (Figure 1).
The HMGB1 inside the cell (nucleus or cytosol) is completely reduced, and early prevalence of fully reduced HMGB1 and subsequenct appearance of disulfide HMGB1 were observed in models of brain, muscle, or liver injuries and in patients with Juvenile Idiopathic Arthritis $(19,39,41)$. Supernatants from LPS-activated THP-1 monocytic cells contain both fully reduced and disulfide HMGB1 (38), suggesting that activated monocytes/macrophages contribute to inflammation by producing disulfide HMGB1. Tandem mass-spectrometric analysis showed that systemic levels of the disulfide HMGB1 isoform dramatically increased during early Macrophages Activation Syndrome (43). Similarly, a study revealed that cells undergoing unprimed pyroptosis release a reduced HMGB1 redox isoform, whereas priming with TLRs ligands results in the conversion to disulfide HMGB1 (44).

In conclusion, it is now essential to identify the redox state of HMGB1 in each specific condition and locale in vivo.

\section{ATP, a Time-Resolved DAMP}

Nucleotides as well, particularly ATP, have both intra- and extracellular roles. They are well known for their function as a universal energy source in cell reactions and metabolism. The multiple functions of extracellular ATP have been known since the late 1940s, when its vasoactive property and its release in shock were discovered [reviewed by Gordon (45)]. Later, ATP was found to be released at nerve terminals, affecting smooth muscle tone. Moreover, ATP and adenosine are involved in the mechanisms underlying local control of vessel tone, while ADP induces platelet aggregation and is released, together with ATP, from platelet granules (45). Several cell types release ATP during inflammatory, ischemic, and hypoxic conditions. ATP release can occur in a passive fashion, for example during necrosis, but many molecular pathways have been described for active release, as ATP-containing lysosome exocytosis from astrocytes, pannexin-mediated ATP release during apoptosis, and connexinor pannexin-mediated ATP release from inflammatory cells, such as neutrophils (46). Moreover, it has been recently demonstrated that ATP can also be secreted by dying cancer cells through the classical endoplasmic reticulum/Golgi secretory pathway (47).

In the extracellular compartment, nucleotide signaling is intrinsically short-lived. Signaling is terminated in the timescale from seconds to minutes by the enzymatic conversion of ATP to adenosine through the ecto-nucleoside triphosphate diphosphohydrolase CD39 (from ATP/ADP to AMP) and the ecto-5' -nucleotidase CD73 (from AMP to adenosine) (48). ATP acts as a signaling molecule through the activation of purinergic P2 receptors (9). These receptors have a widespread expression throughout different tissues and are involved in innate and adaptive immune responses $(46,48)$. P2 receptors can be further subdivided into metabotropic P2Y receptors (P2YRs), which are G-protein-coupled, and ionotropic P2X receptors (P2XRs), which are nucleotide-gated ion channels.

P2YR signaling has been linked with chronic inflammation, and one of the most studied receptor of this class is P2Y2R, which is activated by UTP or ATP. P2Y2R agonists promote mucociliary clearance and wound healing [reviewed by Idzko et al. (9)]. For these reasons, P2YR agonists were exploited for the treatment of cystic fibrosis (49). Apoptotic cells release ATP 


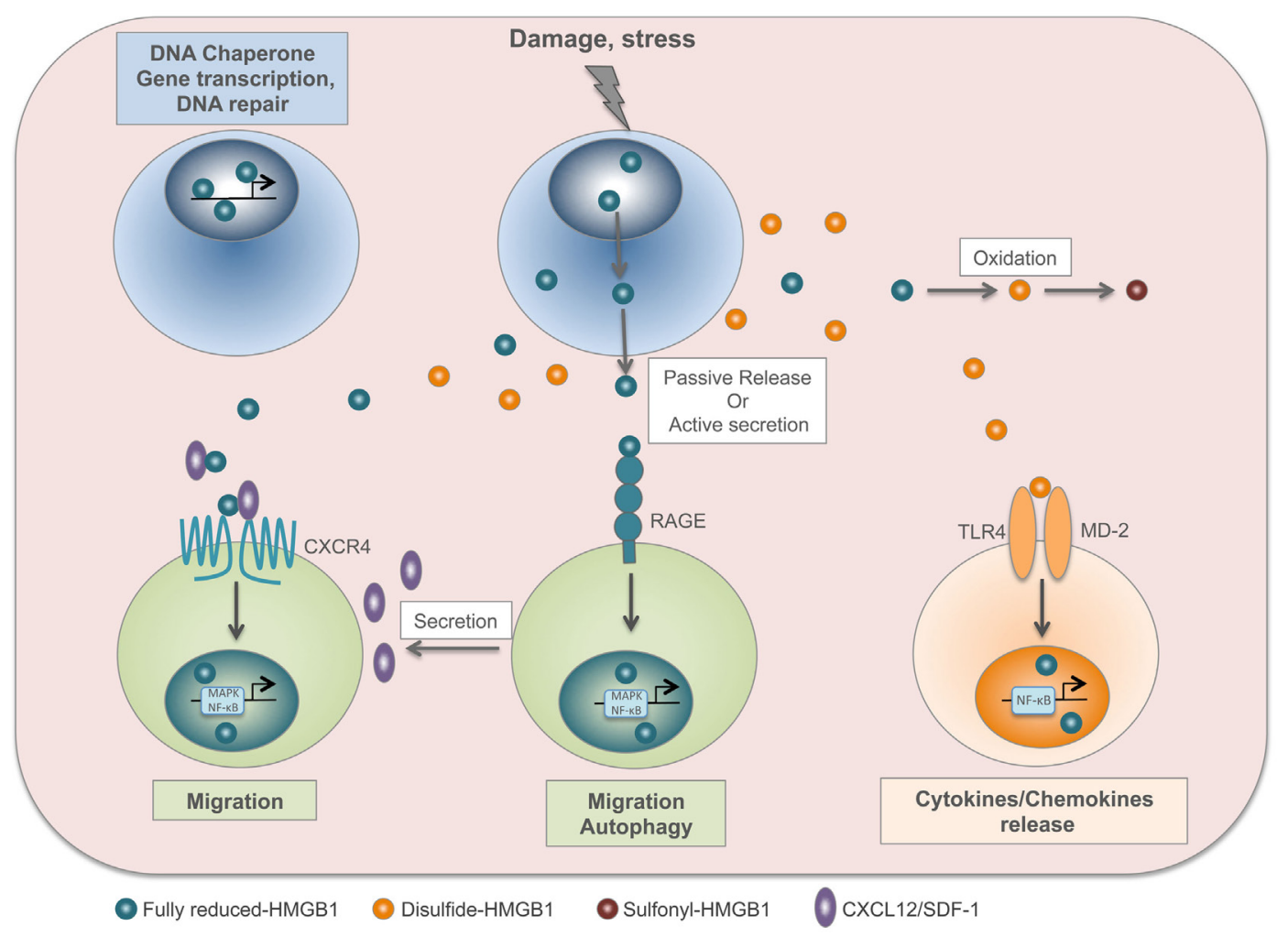

FIGURE 1 | HMGB1 is a redox-sensitive DAMP. In the nucleus, fully reduced HMGB1 acts as a DNA chaperone and contributes to gene transcription and DNA repair. Upon injury or stress, HMGB1 is passively released by dead cells or actively secreted by stressed cells. The fully reduced HMGB1 binds to CXCL12 chemokine to form a heterocomplex, which in turn binds to CXCR4 and induces cell migration. In addition, HMGB1 interacts with
RAGE to induce CXCL12 secretion and autophagy. In the extracellular compartment, disulfide HMGB1 derives from the active secretion and/or the conversion of fully reduced HMGB1 by oxidation. Disulfide HMGB1 binds to TLR4/MD-2 complex and induces cytokine/chemokine release. Finally, HMGB1 cysteines are terminally oxidized to sulfonates; sulfonyl-HMGB1 is neither chemoattractant nor has cytokine-inducing activity. as a "find-me" signal that binds P2Y2R on macrophages, stimulating their phagocytic activity and the clearance of apoptotic cells (50). During pneumonia, neutrophil-dependent ATP release and autocrine activation of $\mathrm{P} 2 \mathrm{Y} 2 \mathrm{R}$ contribute to purinergic chemotaxis, thereby enhancing bacterial clearance (51). However, ATPelicited P2Y2R signaling can lead to uncontrolled inflammation and chronic inflammatory diseases. On alveolar epithelial cells or eosinophils, P2Y2R signaling causes production of pro-allergic mediators (for example, IL-33, IL-8, eosinophil cationic protein) during allergic airway disease (52). Similarly, P2Y2R signaling on DC has a role during the induction and self-perpetuation of asthma (53). In general, P2Y2R antagonists can evolve into useful drugs for chronic inflammatory diseases.

P2XR channels are opened by the binding of ATP, allowing sodium and calcium influx and potassium efflux. The increased level of intracellular calcium activates $\mathrm{p} 38 \mathrm{MAPK}$ or phospholipase A2 signaling, while potassium efflux activates the inflammasome (9). Then, P2XR channels gradually dilate into pores permeable to larger organic cations and small hydrophilic molecules with a molecular mass below 900 dalton (including ATP) (54). Among P2XRs, P2X7R is predominantly expressed on immune cells such as mast cells, macrophages, microglia, and DCs, and its signaling has been linked to inflammatory and infectious disorders (46).
$\mathrm{P} 2 \mathrm{X} 7 \mathrm{R}$ is required for appropriate inflammatory defense mechanism against invading pathogens and cancer cells. For instance, it is important during intracellular killing of Mycobacterium tuberculosis by macrophages (55). Dying tumor cells release ATP that activates $\mathrm{P} 2 \mathrm{X} 7 \mathrm{R}$ on DCs, which in turn promote the priming of IFN- $\gamma$-producing cytotoxic $\mathrm{CD}^{+} \mathrm{T}$ cells that kill cancer cells (56). On the other hand, P2X7R signaling contributes to the induction and maintenance of chronic inflammation. Indeed, P2X7R signaling on DCs is involved in the sensitization phase of allergic disorders such as contact hypersensitivity (through CD81 T-cell priming) (57) and asthma (through CD41 T-cells, TH2 response) (58), and contributes to transplant rejection (through CD41 T cells, TH1 response) (59). Furthermore, P2X7R signaling on enteric neurons or mast cells has been implicated in promoting intestinal inflammation during inflammatory bowel disease (60) (Figure 2).

As already mentioned, the binding of extracellular ATP to P2X7R elicits NLRP3 activation (21). The contribution of the $\mathrm{ATP} / \mathrm{P} 2 \mathrm{X} 7$ receptor axis to inflammasome activation in pathogenic conditions has been shown in a bleomycin model of pulmonary inflammation in mice. This leads to IL- $1 \beta$ maturation and secretion, causing lung inflammation that evolves to fibrosis (61). Moreover, P2X7R upregulation in atherosclerotic lesions in mice 


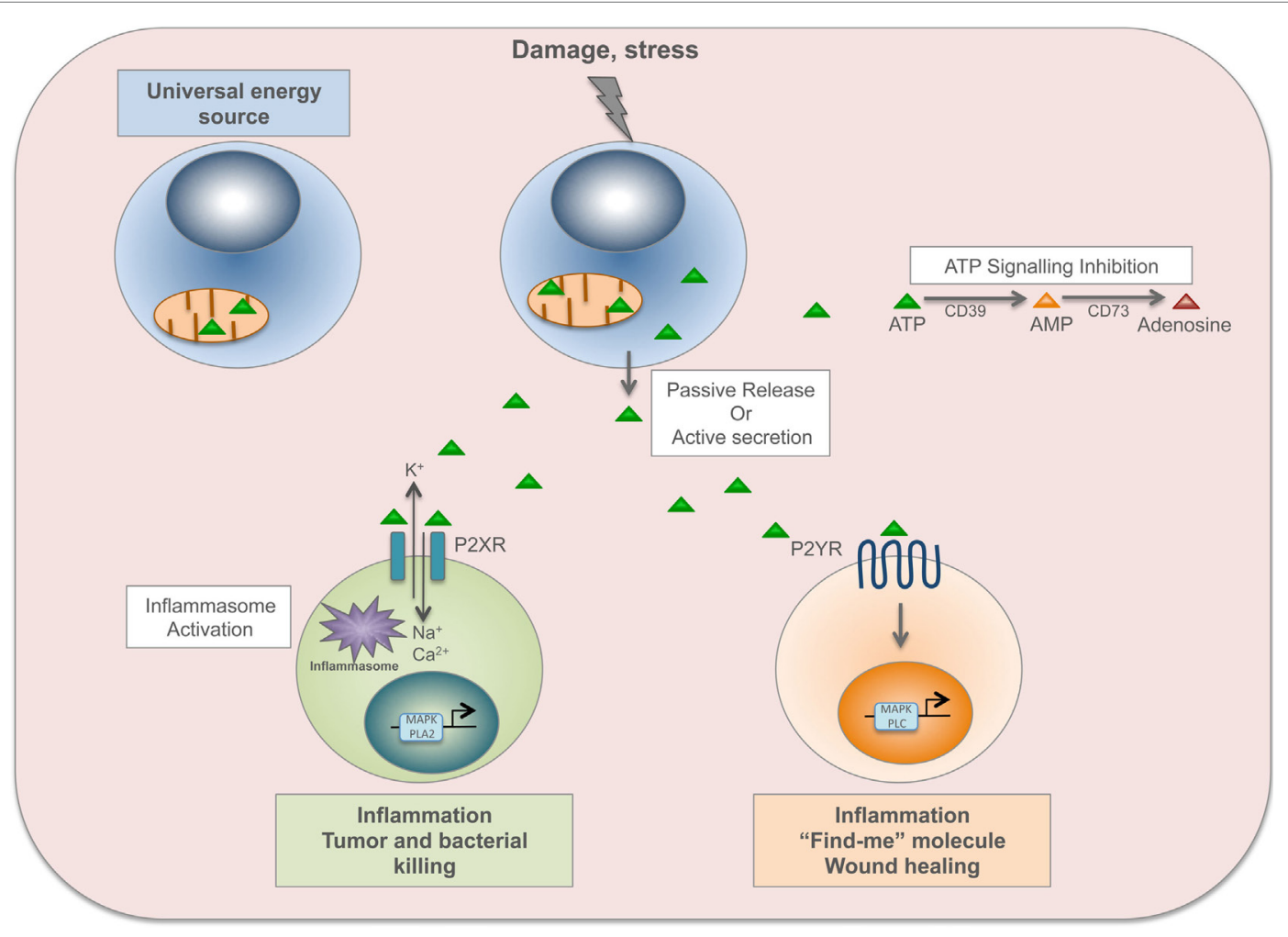

FIGURE 2 | ATP is a time-resolved DAMP. In the cell, ATP derived from mitochondria is a universal energy source in cell reactions and metabolism. Upon damage or stress, ATP, and other nucleotides, are passively released by dead cells or actively secreted by stressed cells. ATP binds to ionotropic $\mathrm{P} 2 \mathrm{X}$ receptors $(\mathrm{P} 2 \mathrm{XR})$, which are nucleotide-gated ion channels, allowing sodium $\left(\mathrm{Na}^{+}\right)$and calcium $\left(\mathrm{Ca}^{2+}\right)$ influx and potassium $\left(\mathrm{K}^{+}\right)$efflux. The increased level of intracellular calcium activates p38 MAPK or phospholipase A2 signaling, while potassium efflux activates the inflammasome. P2XR signaling is involved in inflammation, tumor and bacterial killing. ATP also binds to metabotropic P2Y receptors (P2YR), which are G-protein-coupled, and induces activation of MAPK and phospholipase C (PLC). P2YR signaling is implicated in inflammation and wound healing, and ATP released by apoptotic cells acts as a "find-me" signal to recruit macrophages to the site of damage and to promote clearance of apoptotic cells. ATP signaling is abolished by the enzymatic conversion of ATP to adenosine through the ecto-nucleoside triphosphate diphosphohydrolase CD39 (from ATP to AMP) and the ecto-5'-nucleotidase CD73 (from AMP to adenosine). modulates NLRP3 inflammasome activation, and is involved in the progression and development of atherosclerosis (62).

As we reviewed in this chapter, DAMPs, in particular HMGB1 and ATP, have been linked to inflammation and related disorders. Hence, inhibition of DAMP-mediated inflammatory responses might appear as a promising strategy to improve the clinical management of infection- and injury-elicited inflammatory diseases. However, it is important to keep in mind that these sophisticated molecules are danger signals important not only for the inflammatory response but also for tissue repair. Here, we review the latest findings on the regenerative properties of HMGB1 and ATP.

\section{HMGB1 and ATP in Tissue Repair}

The functions of DAMPs consist in alerting the body about danger, stimulating the immune system in order to initiate the immune response, and finally promoting the regeneration process. This last property of DAMPs has been particularly investigated for two members of the family: HMGB1 and ATP (Figure 3).

\section{HMGB1, a Chemotactic and Proangiogenic DAMP}

HMGB1 plays an important role in promoting tissue regeneration after acute inflammation. Locally released HMGB1 recruits bonemarrow derived mesenchymal stem cells (MSCs), and promotes the proliferation and differentiation of tissue-associated resident stem cells, such as dental pulp stem cells, mesoangioblasts, and MSCs (63). Adult MSCs have attracted intense interest because they can be isolated from the bone marrow and can be expanded in culture while maintaining their multipotency, and thus may be used for the repair of bone, cartilage, muscle, bone marrow stroma, tendon, fat, and other connective tissues. HMGB1 induces migration of MSC (64-66) and their differentiation into osteoblasts (64). Moreover, intravenous administration of HMGB1 in mice induces MSC accumulation in skin grafts, promoting inflammatory suppression in the grafts, and subsequent tissue regeneration (67). However, a recent study showed that HMGB1 induces migration of monocytes but not of MSCs (68). Further experiments are necessary in order to understand these discrepancies, in particular, the culture conditions that 


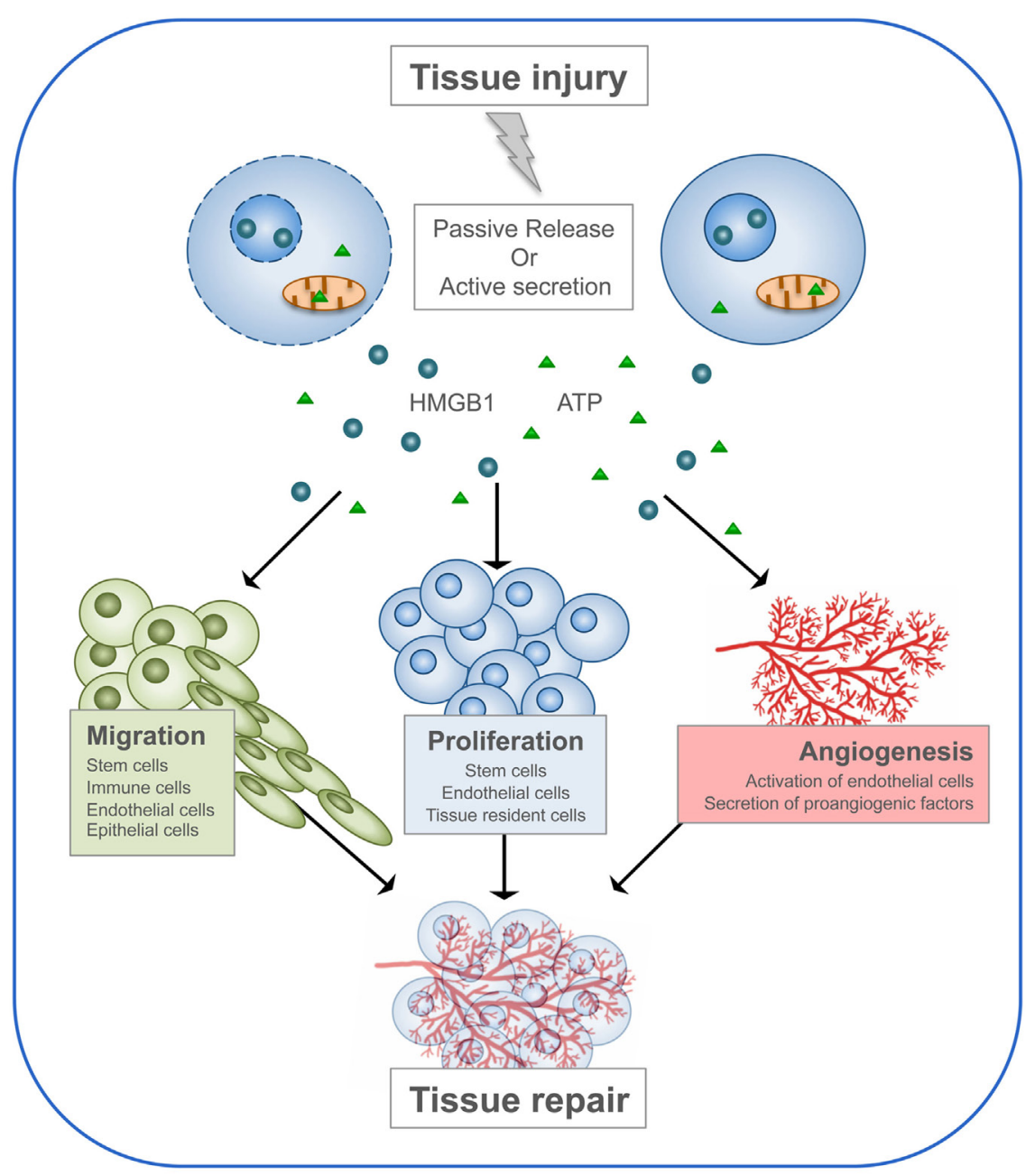

FIGURE 3 | HMGB1 and ATP in tissue repair. Following tissue injury, HMGB1 and ATP are passively released by dead cells or actively secreted by stressed cells. Then, they recruit to the site of damage the cell types required to heal the wound. First, immune cells are needed to clean the wound by engulfing dead cells and cellular debris. Then, stem cells and neighboring cells are induced to proliferate and build new tissue, together with its extracellular matrix. Endothelial cells are activated to form new blood vessels. could modulate the redox state of HMGB1 and consequently its chemotactic activity.

Tissue repair requires angiogenesis, and numerous studies have identified HMGB1 as a proangiogenic factor [recently reviewed by Yang et al. (69)]. Briefly, HMGB1 plays an important role in neovascularization of ischemic areas by recruiting endothelial progenitor cells through activation of integrins and inducing the migration and sprouting of endothelial cells in a RAGE-dependent manner (70, 71). In addition, HMGB1 stimulates endothelial cells and macrophages to release proangiogenic cytokines, such as VEGF, TNF- $\alpha$, and IL-8 (72). HMGB1 secreted by leukocytes is important for the skeletal muscle to react to hypoxia and to initiate angiogenesis in response to injury (73).

The regenerative properties of HMGB1 have been studied in different models of tissue injury, including spinal cord, skin, muscle, and heart. In a model of spinal cord injury in zebrafish, the authors observed that HMGB1 expression increases after injury in both motoneurons and endothelial cells. Moreover, inhibition of HMGB1 decreases locomotor recovery and axonal formation (74). In a model of spontaneous spinal cord regeneration in the gecko, HMGB1 does not mediate the inflammatory response but promotes regeneration. Here, HMGB1 induces migration of oligodendrocytes by interacting with RAGE, but not TLRs (75).

In skin, HMGB1 was identified as a chemoattractant for bone marrow-derived epithelial progenitors, which contribute to epithelial regeneration (67). A well-known consequence of diabetes is impaired skin wound repair, and topical treatment with recombinant fully reduced HMGB1 accelerated wound healing in diabetic mice (76). Accordingly, HMGB1 levels are low in diabetic human and mouse skin, and inhibition of endogenous HMGB1 impaired wound healing in non-diabetic mice but had no effect in diabetic mice. Conversely, HMGB1 also plays a role in scar formation in fetal skin (77). Interestingly, the authors used a 
recombinant HMGB1 described to induce TNF release, suggesting that it corresponds to the disulfide form.

In a mouse model of acute myocardial infarction, overexpression of HMGB1 in cardiac cells or local administration of HMGB1 induced myocardial regeneration, restored cardiac function, and improved survival $(78,79)$. These effects were due to proliferation and differentiation of cardiac stem cells and induction of angiogenesis. Moreover, HMGB1 stimulates primary cardiac fibroblasts to exert a paracrine action on cardiac stem cells (80), and intramyocardial injection of HMGB1 improved global cardiac function by reducing fibrosis and cardiomyocyte hypertrophy (81). HMGB1 activates a number of genes involved in cardiac protection and regeneration, and Notch 1 signaling plays a key role in HMGB1 ability to activate cardiac stem cells (82). Interestingly, beneficial effects of HMGB1 were also observed in models of heart failure (81-83). Conversely, HMGB1 blockade caused an expansion of the infarct scar and marked hypertrophy of the non-infarcted area (84).

Finally, HMGB1 is important in skeletal muscle regeneration. The presence of only half of the normal amount of HMGB1 results in defective myogenesis both during development and after acute injury (85). In particular, the absence of HMGB1 in leukocytes results in defective angiogenesis and a delay in muscle regeneration (73). HMGB1 levels are increased in regenerating skeletal muscle after ischemia/reperfusion, and intramuscular administration of HMGB1 enhances both vascularization and myofiber formation (86). Besides angiogenesis, HMGB1 also promotes myogenesis by stimulating migration and proliferation of mesoangioblasts and migration of skeletal myoblasts and smooth muscle cells, and by accelerating myogenic differentiation (86-89).

In conclusion, HMGB1 released by injured tissues promotes tissue repair by inducing migration and proliferation of stem cells, and by promoting angiogenesis. However, several studies have demonstrated the beneficial effect of blocking HMGB1 in animal models of spinal cord, liver, brain, and myocardial damage after ischemia/reperfusion injury (24). Indeed, HMGB1 also activates fibroblasts and astrocytes, which might induce fibrosis as a program of tissue consolidation if successful regeneration is not achieved. The discrepancy between these results might be due to the fact that the redox state of HMGB1 has not been rigorously identified in most of the studies reported. Indeed, even if the fully reduced HMGB1 is the most used recombinant form, the reduced and disulfide forms can easily interconvert both in vitro and in vivo.

\section{Nucleotides as "Find-Me" Signals in Tissue Repair}

The interplay between nucleotides and the immune system is essential for regenerative processes in the body $(46,90)$. During tissue regeneration, the organism needs to remove dead cells and debris to recruit various types of cells and to stimulate their proliferation in order to achieve wound closure. Nucleotides participate actively to these three phases by interacting with purinergic receptors on different cell types.

The two families of P2Rs appear to have separate roles: P2XRs are involved in defense mechanisms and cell death, and P2YRs in wound healing (9). Indeed, prevalently P2YRs have been studied in different models of tissue regeneration. Both ATP and UTP released by apoptotic cells in a caspase-1-dependent manner act as "find-me" signals that recruit macrophages through P2Y2R, and stimulate their phagocytic activity (50). Neutrophils release ATP that in turn recruits neutrophils, in a feed forward loop (51). In addition, both ATP and UTP promote migration of vascular smooth muscle cells through binding of P2Y2R to filamin A (91).

Stimulation of $\mathrm{P} 2 \mathrm{Y}$ receptors has a mitogenic effect on multiple cell types, including brain capillary endothelial cells (92), cardiac endothelial cells (93), and fibroblasts (94). Non-hydrolyzable nucleotide analogs (e.g., ATP $\gamma \mathrm{S}, \mathrm{ADP} \beta \mathrm{S}$ ) strongly promote proliferation of HUVEC cells and of mammalian vascular smooth muscular cells (95). These observations strongly suggest that nucleotide might be proangiogenic factors important for tissue repair.

Nucleotide release from dying cells after acute kidney injury induces proliferation of neighboring tubular cells, thus promoting wound closure via the downstream activation of Akt (96). In the liver, ATP released after partial hepatectomy, both from hepatocytes and from Kupffer cells, contributes to liver regeneration by activating cell cycle progression in hepatocytes (97). Calcium waves elicited by ATP released from damaged cells are important in the developing brain of Xenopus laevis, where neural progenitor cells reorganize their cytoskeleton and activate the actomyosin contractile machinery to drive the expulsion of damaged cells into the brain ventricle. This represents a mechanism for rapid wound healing in the developing brain (98).

Shockwave treatment is a new technology used to treat chronic painful conditions of the musculoskeletal system. Shockwaves induce ATP release, which leads to Erk1/2 and p38 MAPK activation and cell proliferation, and increased wound healing in a rat model (99). During skin wound healing, extracellular nucleotides have a dual function: they inhibit keratinocyte motility and facilitate migration of other cell types (e.g., endothelial cells) $(100,101)$. Treatment of mouse ear wounds with Mg-ATP encapsulated in lipid vesicles (ATP-vesicles) induced macrophage accumulation, in situ proliferation and new tissue growth (102). ATP release from $\mathrm{HaCaT}$ keratinocytes caused the propagation of intercellular calcium waves from cells at the frontier facing the scar toward the cells in the rear, in a P2Y-receptor-dependent manner (103). Finally, the most striking evidence of P2YR signaling in tissue repair is the delay of wound healing observed in P2y $2 r^{-1-}$ mice (94).

In zebrafish larvae, when the tail fin is wounded, osmolarity differences between the interstitial fluid and the ambient water trigger ATP release, which initiates rapid wound closure through long-range activation of basal epithelial cell motility. In this case, P2Y2R is probably irrelevant, since the P2Y2R inhibitor suramin had little effect, even at high concentrations (104). Indeed, wound healing is known to involve other purinergic receptors. In cystic fibrosis, ATP release from epithelial cells activates P2RY11 on nearby epithelial cells, stimulating proliferation, migration and wound repair (105). P2X7 activation participates in angiogenesis and wound repair by promoting VEGF release from human monocytes (106). Moreover, P2X7 is necessary for timely healing of abrasion wounds and normal stromal collagen structure (107). 
Acute UV irradiation of keratinocytes causes ATP release that triggers P2X7R on skin-resident T cells and participates to DNA repair response essential for skin regeneration (108). Thus, even P2XRs might switch from their killing activity, opening pores on the plasma membrane that cause the cell to collapse, to a proregenerative function, helping tissue repair.

\section{Conclusion and Future Directions}

Nature is remarkably conservative, in that it uses the same molecule over and over again to attain related goals (109). DAMPs are exemplary from this point of view, as they are (generally abundant) molecules that are involved in the everyday functioning of the cell, and double up as signals of cell damage when they are present outside of the cell. As it happens, this simple invention that allowed to discern damage (DAMP-out) from normality (DAMP-in), could be used further to better describe the nature of the damage, and to record its occurrence for future memory. Thus, after being released (either passively or actively), DAMPs act to:

(1) convey the message of danger to other cells,

(2) trigger inflammation and activate innate immunity to stop the damage,

(3) participate in cell-cell communication that instructs adaptive immunity, to help establish immunological memory,

(4) orchestrate tissue repair and healing.

Points (1) and (2) have been widely described (7, 110). The cooptation of DAMPs into the process of immunological memory (point 3) and the related process of Immunogenic Cell Death are the subject of other reviews in this Frontiers collection. Immunogenic cell death is a perfect example of interplay between several DAMPs to alert and activate the immune system.

Here, we have focused on the role played by ATP and HMGB1 in wound repair and tissue reconstruction. ATP and other nucleotides, and their purinergic receptors, have been known to participate in tissue repair since the late 1990s, even before they were recognized as DAMPs. Examples involving HMGB1 are now as numerous. However, a fundamental problem must be acknowledged: how can the organism use the same DAMPs

\section{References}

1. Janeway CA. Approaching the asymptote? Evolution and revolution in immunology. Cold Spring Harb Symp Quant Biol (1989) 54(Pt 1):1-13. doi:10.1101/SQB.1989.054.01.003

2. Matzinger P. Tolerance, danger, and the extended family. Annu Rev Immunol (1994) 12:991-1045. doi:10.1146/annurev.iy.12.040194.005015

3. Land W, Schneeberger H, Schleibner S, Illner WD, Abendroth D, Rutili G, et al. The beneficial effect of human recombinant superoxide dismutase on acute and chronic rejection events in recipients of cadaveric renal transplants. Transplantation (1994) 57:211-7. doi:10.1097/00007890-199401001-00010

4. Scaffidi P, Misteli T, Bianchi ME. Release of chromatin protein HMGB1 by necrotic cells triggers inflammation. Nature (2002) 418:191-5. doi:10.1038/ nature00858

5. Shi Y, Evans JE, Rock KL. Molecular identification of a danger signal that alerts the immune system to dying cells. Nature (2003) 425:516-21. doi:10.1038/ nature 01991 to trigger inflammation and to orchestrate tissue repair, which should occur after resolution of inflammation? Here, we can only speculate, and perhaps suggest future avenues of research. Usually, a signal with two possible meanings must be disambiguated by either the state of the receiver or the context of the signaling. Thus, to disambiguate the DAMP in inflammation and tissue repair, cells would need two different receptors, on different cells or on the same cell but at different times. Perhaps relevant here is that RAGE, a receptor for HMGB1, is low at the beginning of inflammation and induced by it.

Context in signaling is easy to picture: contextuality is paramount in everyday human communication. In the case of inflammation and tissue repair, context is the co-presence of other ligand-receptor pairs in different situations, in addition to the DAMP and its receptor, so that cells are differently activated or polarized. In fact, inflammation creates a microenvironment that is acidic, oxidizing (rich in oxygen and ROS), and where the metabolism of inflammatory cells is shifted toward glycolysis, whereas tissue repair occurs in a microenvironment which is neutral, reducing, and where macrophage metabolism is shifted towards oxidative phosphorylation and fatty acid oxidation $(111,112)$.

Also notable is that tissue reconstruction and inflammation, or at least some aspects of both, occur simultaneously in chronically inflamed tissue. In situations like rheumatoid arthritis, where inflammation is rampant and the synovia grows exuberantly into a pannus, DAMPs might not be disambiguated, and might actually activate both programs at the same time. Not surprisingly, targeting DAMPs or their receptors during chronic inflammation is often beneficial. However, finely tuning might be better than blocking them altogether. Thus, better understanding of the activity and the interaction of cells in inflammation and tissue reconstruction, and of DAMP signaling, is key to control excessive inflammation, resolve chronic inflammation, and promote tissue repair and healing.

\section{Acknowledgments}

This work was supported by grants from the Associazione Italiana Ricerca sul Cancro (IG - 10411 to MB) and Ministero della Salute (GR-2011-02351814 to EV).

6. Schaefer L. Complexity of danger: the diverse nature of damage-associated molecular patterns. J Biol Chem (2014) 289:35237-45. doi:10.1074/jbc. R114.619304

7. Bianchi ME. DAMPs, PAMPs and alarmins: all we need to know about danger. J Leukoc Biol (2007) 81:1-5. doi:10.1189/jlb.0306164

8. Lopetuso LR, Scaldaferri F, Pizarro TT. Emerging role of the interleukin (IL)33/ST2 axis in gut mucosal wound healing and fibrosis. Fibrogenesis Tissue Repair (2012) 5:18. doi:10.1186/1755-1536-5-18

9. Idzko M, Ferrari D, Eltzschig HK. Nucleotide signalling during inflammation. Nature (2014) 509:310-7. doi:10.1038/nature13085

10. Krysko DV, Garg AD, Kaczmarek A, Krysko O, Agostinis P, Vandenabeele P. Immunogenic cell death and DAMPs in cancer therapy. Nat Rev Cancer (2012) 12:860-75. doi:10.1038/nrc3380

11. Krysko DV, Agostinis P, Krysko O, Garg AD, Bachert C, Lambrecht BN, et al. Emerging role of damage-associated molecular patterns derived from mitochondria in inflammation. Trends Immunol (2011) 32:157-64. doi:10.1016/j. it.2011.01.005 
12. Wang H, Bloom O, Zhang M, Vishnubhakat JM, Ombrellino M, Che J, et al. HMG-1 as a late mediator of endotoxin lethality in mice. Science (1999) 285:248-51. doi:10.1126/science.285.5425.248

13. Gardella S, Andrei C, Ferrera D, Lotti LV, Torrisi MR, Bianchi ME, et al. The nuclear protein HMGB1 is secreted by monocytes via a non-classical, vesicle-mediated secretory pathway. EMBO Rep (2002) 3:995-1001. doi:10.1093/ embo-reports/kvf198

14. Eltzschig HK, Macmanus CF, Colgan SP. Neutrophils as sources of extracellular nucleotides: functional consequences at the vascular interface. Trends Cardiovasc Med (2008) 18:103-7. doi:10.1016/j.tcm.2008.01.006

15. Gardai SJ, McPhillips KA, Frasch SC, Janssen WJ, Starefeldt A, MurphyUllrich JE, et al. Cell-surface calreticulin initiates clearance of viable or apoptotic cells through trans-activation of LRP on the phagocyte. Cell (2005) 123:321-34. doi:10.1016/j.cell.2005.08.032

16. Bianchi ME, Agresti A. HMG proteins: dynamic players in gene regulation and differentiation. Curr Opin Genet Dev (2005) 15:496-506. doi:10.1016/j. gde.2005.08.007

17. Lu B, Wang C, Wang M, Li W, Chen F, Tracey KJ, et al. Molecular mechanism and therapeutic modulation of high mobility group box 1 release and action: an updated review. Expert Rev Clin Immunol (2014) 10:713-27. doi:10.1586/ 1744666X.2014.909730

18. Bonaldi T, Talamo F, Scaffidi P, Ferrera D, Porto A, Bachi A, et al. Monocytic cells hyperacetylate chromatin protein HMGB1 to redirect it towards secretion. EMBO J (2003) 22:5551-60. doi:10.1093/emboj/cdg516

19. Antoine DJ, Jenkins RE, Dear JW, Williams DP, McGill MR, Sharpe MR, et al. Molecular forms of HMGB1 and keratin-18 as mechanistic biomarkers for mode of cell death and prognosis during clinical acetaminophen hepatotoxicity. J Hepatol (2012) 56:1070-9. doi:10.1016/j.jhep.2011.12.019

20. Lu B, Wang H, Andersson U, Tracey KJ. Regulation of HMGB1 release by inflammasomes. Protein Cell (2013) 4:163-7. doi:10.1007/s13238-012-2118-2

21. Gombault A, Baron L, Couillin I. ATP release and purinergic signaling in NLRP3 inflammasome activation. Front Immunol (2013) 3:414. doi:10.3389/ fimmu.2012.00414

22. Frank MG, Weber MD, Watkins LR, Maier SF. Stress sounds the alarmin: the role of the danger-associated molecular pattern HMGB1 in stress-induced neuroinflammatory priming. Brain Behav Immun (2015) 48:1-7. doi:10.1016/j.bbi.2015.03.010

23. Geng Y, Ma Q, Liu Y-N, Peng N, Yuan F-F, Li X-G, et al. Heatstroke induces liver injury via IL-1 $\beta$ and HMGB1-induced pyroptosis. J Hepatol (2015). doi:10.1016/j.jhep.2015.04.010

24. Andersson U, Tracey KJ. HMGB1 is a therapeutic target for sterile inflammation and infection. Annu Rev Immunol (2011) 29:139-62. doi:10.1146/ annurev-immunol-030409-101323

25. Parkkinen J, Raulo E, Merenmies J, Nolo R, Kajander EO, Baumann M, et al. Amphoterin, the $30-\mathrm{kDa}$ protein in a family of HMG1-type polypeptides. Enhanced expression in transformed cells, leading edge localization, and interactions with plasminogen activation. J Biol Chem (1993) 268:19726-38.

26. Kierdorf K, Fritz G. RAGE regulation and signaling in inflammation and beyond. J Leukoc Biol (2013) 94:55-68. doi:10.1189/jlb.1012519

27. Kokkola R, Andersson A, Mullins G, Ostberg T, Treutiger C-J, Arnold $\mathrm{B}$, et al. RAGE is the major receptor for the proinflammatory activity of HMGB1 in rodent macrophages. Scand J Immunol (2005) 61:1-9. doi:10.1111/j.0300-9475.2005.01534.x

28. Fiuza C, Bustin M, Talwar S, Tropea M, Gerstenberger E, Shelhamer JH, et al. Inflammation-promoting activity of HMGB1 on human microvascular endothelial cells. Blood (2003) 101:2652-60. doi:10.1182/blood-2002-05-1300

29. Schiraldi M, Raucci A, Muñoz LM, Livoti E, Celona B, Venereau E, et al. HMGB1 promotes recruitment of inflammatory cells to damaged tissues by forming a complex with CXCL12 and signaling via CXCR4. J Exp Med (2012) 209:551-63. doi:10.1084/jem.20111739

30. Tian J, Avalos AM, Mao S-Y, Chen B, Senthil K, Wu H, et al. Toll-like receptor 9-dependent activation by DNA-containing immune complexes is mediated by HMGB1 and RAGE. Nat Immunol (2007) 8:487-96. doi:10.1038/ni1457

31. Urbonaviciute V, Fürnrohr BG, Meister S, Munoz L, Heyder P, De Marchis F, et al. Induction of inflammatory and immune responses by HMGB1nucleosome complexes: implications for the pathogenesis of SLE. J Exp Med (2008) 205:3007-18. doi:10.1084/jem.20081165

32. Wang X, Sun R, Wei H, Tian Z. High-mobility group box 1 (HMGB1)toll-like receptor (TLR)4-interleukin (IL)-23-IL-17A axis in drug-induced damage-associated lethal hepatitis: interaction of $\gamma \delta \mathrm{T}$ cells with macrophages. Hepatology (2013) 57:373-84. doi:10.1002/hep.25982

33. Yang Z, Deng Y, Su D, Tian J, Gao Y, He Z, et al. TLR4 as receptor for HMGB1mediated acute lung injury after liver ischemia/reperfusion injury. Lab Invest (2013) 93:792-800. doi:10.1038/labinvest.2013.66

34. Weng H, Deng Y, Xie Y, Liu H, Gong F. Expression and significance of HMGB1, TLR4 and NF- $\mathrm{\kappa B}$ p65 in human epidermal tumors. BMC Cancer (2013) 13:311. doi:10.1186/1471-2407-13-311

35. Maroso M, Balosso S, Ravizza T, Liu J, Aronica E, Iyer AM, et al. Toll-like receptor 4 and high-mobility group box-1 are involved in ictogenesis and can be targeted to reduce seizures. Nat Med (2010) 16:413-9. doi:10.1038/ $\mathrm{nm} .2127$

36. Antoine DJ, Harris HE, Andersson U, Tracey KJ, Bianchi ME. A systematic nomenclature for the redox states of high mobility group box (HMGB) proteins. Mol Med (2014) 20:135-7. doi:10.2119/molmed.2014.00022

37. Yang H, Wang H, Ju Z, Ragab AA, Lundbäck P, Long W, et al. MD-2 is required for disulfide HMGB1-dependent TLR4 signaling. J Exp Med (2015) 212:5-14. doi:10.1084/jem.20141318

38. Venereau E, Casalgrandi M, Schiraldi M, Antoine DJ, Cattaneo A, De Marchis F, et al. Mutually exclusive redox forms of HMGB1 promote cell recruitment or proinflammatory cytokine release. J Exp Med (2012) 209:1519-28. doi:10.1084/jem.20120189

39. Liesz A, Dalpke A, Mracsko E, Antoine DJ, Roth S, Zhou W, et al. DAMP signaling is a key pathway inducing immune modulation after brain injury. $J$ Neurosci (2015) 35:583-98. doi:10.1523/JNEUROSCI.2439-14.2015

40. Harris HE, Andersson U, Pisetsky DS. HMGB1: a multifunctional alarmin driving autoimmune and inflammatory disease. Nat Rev Rheumatol (2012) 8:195-202. doi:10.1038/nrrheum.2011.222

41. Lundbäck P, Stridh P, Klevenvall L, Jenkins RE, Fischer M, Sundberg E, et al. Characterization of the inflammatory properties of actively released HMGB1 in juvenile idiopathic arthritis. Antioxid Redox Signal (2015). doi:10.1089/ ars.2014.6039

42. Agalave NM, Larsson M, Abdelmoaty S, Su J, Baharpoor A, Lundbäck P, et al. Spinal HMGB1 induces TLR4-mediated long-lasting hypersensitivity and glial activation and regulates pain-like behavior in experimental arthritis. Pain (2014) 155:1802-13. doi:10.1016/j.pain.2014.06.007

43. Palmblad K, Schierbeck H, Sundberg E, Horne A-C, Harris HE, Henter J-I, et al. High systemic levels of the cytokine-inducing HMGB1 isoform secreted in severe macrophage activation syndrome. Mol Med (2014) 20:538-47. doi:10.2119/molmed.2014.00183

44. Nyström S, Antoine DJ, Lundbäck P, Lock JG, Nita AF, Högstrand K, et al. TLR activation regulates damage-associated molecular pattern isoforms released during pyroptosis. EMBO J (2013) 32:86-99. doi:10.1038/emboj.2012.328

45. Gordon JL. Extracellular ATP: effects, sources and fate. Biochem J (1986) 233:309-19.

46. Junger WG. Immune cell regulation by autocrine purinergic signalling. Nat Rev Immunol (2011) 11:201-12. doi:10.1038/nri2938

47. Garg AD, Krysko DV, Verfaillie T, Kaczmarek A, Ferreira GB, Marysael T, et al. A novel pathway combining calreticulin exposure and ATP secretion in immunogenic cancer cell death. EMBO J (2012) 31:1062-79. doi:10.1038/ emboj.2011.497

48. Eltzschig HK, Sitkovsky MV, Robson SC. Purinergic signaling during inflammation. N Engl J Med (2012) 367:2322-33. doi:10.1056/NEJMra1205750

49. Knowles MR, Clarke LL, Boucher RC. Activation by extracellular nucleotides of chloride secretion in the airway epithelia of patients with cystic fibrosis. $N$ Engl J Med (1991) 325:533-8. doi:10.1056/NEJM199108223250802

50. Elliott MR, Chekeni FB, Trampont PC, Lazarowski ER, Kadl A, Walk SF, et al. Nucleotides released by apoptotic cells act as a find-me signal to promote phagocytic clearance. Nature (2009) 461:282-6. doi:10.1038/nature08296

51. Chen Y, Corriden R, Inoue Y, Yip L, Hashiguchi N, Zinkernagel A, et al. ATP release guides neutrophil chemotaxis via P2Y2 and A3 receptors. Science (2006) 314:1792-5. doi:10.1126/science.1132559

52. Kouzaki H, Iijima K, Kobayashi T, O’Grady SM, Kita H. The danger signal, extracellular ATP, is a sensor for an airborne allergen and triggers IL-33 release and innate Th2-type responses. J Immunol (2011) 186:4375-87. doi:10.4049/jimmunol.1003020

53. Idzko M, Hammad H, van Nimwegen M, Kool M, Willart MAM, Muskens F, et al. Extracellular ATP triggers and maintains asthmatic airway inflammation by activating dendritic cells. Nat Med (2007) 13:913-9. doi:10.1038/nm1617 
54. Surprenant A, Rassendren F, Kawashima E, North RA, Buell G. The cytolytic P2Z receptor for extracellular ATP identified as a P2X receptor (P2X7). Science (1996) 272:735-8. doi:10.1126/science.272.5262.735

55. Placido R, Auricchio G, Falzoni S, Battistini L, Colizzi V, Brunetti E, et al. P2X(7) purinergic receptors and extracellular ATP mediate apoptosis of human monocytes/macrophages infected with Mycobacterium tuberculosis reducing the intracellular bacterial viability. Cell Immunol (2006) 244:10-8. doi:10.1016/j.cellimm.2007.02.001

56. Ghiringhelli F, Apetoh L, Tesniere A, Aymeric L, Ma Y, Ortiz C, et al. Activation of the NLRP3 inflammasome in dendritic cells induces IL-1betadependent adaptive immunity against tumors. Nat Med (2009) 15:1170-8. doi: $10.1038 / \mathrm{nm} .2028$

57. Weber FC, Esser PR, Müller T, Ganesan J, Pellegatti P, Simon MM, et al. Lack of the purinergic receptor P2X(7) results in resistance to contact hypersensitivity. J Exp Med (2010) 207:2609-19. doi:10.1084/jem.20092489

58. Müller T, Vieira RP, Grimm M, Dürk T, Cicko S, Zeiser R, et al. A potential role for P2X7R in allergic airway inflammation in mice and humans. Am J Respir Cell Mol Biol (2011) 44:456-64. doi:10.1165/rcmb.2010-0129OC

59. Wilhelm K, Ganesan J, Müller T, Dürr C, Grimm M, Beilhack A, et al. Graftversus-host disease is enhanced by extracellular ATP activating P2X7R. Nat $\operatorname{Med}(2010)$ 16:1434-8. doi:10.1038/nm.2242

60. Kurashima Y, Amiya T, Nochi T, Fujisawa K, Haraguchi T, Iba H, et al. Extracellular ATP mediates mast cell-dependent intestinal inflammation through P2X7 purinoceptors. Nat Commun (2012) 3:1034. doi:10.1038/ ncomms 2023

61. Riteau N, Gasse P, Fauconnier L, Gombault A, Couegnat M, Fick L, et al. Extracellular ATP is a danger signal activating P2X7 receptor in lung inflammation and fibrosis. Am J Respir Crit Care Med (2010) 182:774-83. doi:10.1164/rccm.201003-0359OC

62. Peng K, Liu L, Wei D, Lv Y, Wang G, Xiong W, et al. P2X7R is involved in the progression of atherosclerosis by promoting NLRP3 inflammasome activation. Int J Mol Med (2015) 35:1179-88. doi:10.3892/ijmm.2015.2129

63. Zhang X, Jiang H, Gong Q, Fan C, Huang Y, Ling J. Expression of high mobility group box 1 in inflamed dental pulp and its chemotactic effect on dental pulp cells. Biochem Biophys Res Commun (2014) 450:1547-52. doi:10.1016/j. bbrc.2014.07.027

64. Meng E, Guo Z, Wang H, Jin J, Wang J, Wang H, et al. High mobility group box 1 protein inhibits the proliferation of human mesenchymal stem cells and promotes their migration and differentiation along osteoblastic pathway. Stem Cells Dev (2008) 17:805-13. doi:10.1089/scd.2008.0276

65. Lotfi R, Eisenbacher J, Solgi G, Fuchs K, Yildiz T, Nienhaus C, et al. Human mesenchymal stem cells respond to native but not oxidized damage associated molecular pattern molecules from necrotic (tumor) material. Eur J Immunol (2011) 41:2021-8. doi:10.1002/eji.201041324

66. Xie H-L, Zhang Y, Huang Y-Z, Li S, Wu C-G, Jiao X-F, et al. Regulation of high mobility group box 1 and hypoxia in the migration of mesenchymal stem cells. Cell Biol Int (2014) 38:892-7. doi:10.1002/cbin.10279

67. Tamai K, Yamazaki T, Chino T, Ishii M, Otsuru S, Kikuchi Y, et al. PDGFRalpha-positive cells in bone marrow are mobilized by high mobility group box 1 (HMGB1) to regenerate injured epithelia. Proc Natl Acad Sci U S A (2011) 108:6609-14. doi:10.1073/pnas.1016753108

68. Vogel S, Börger V, Peters C, Förster M, Liebfried P, Metzger K, et al. Necrotic cell-derived high mobility group box 1 attracts antigen-presenting cells but inhibits hepatocyte growth factor-mediated tropism of mesenchymal stem cells for apoptotic cell death. Cell Death Differ (2015) 22:1219-30. doi:10.1038/cdd.2014.225

69. Yang $\mathrm{S}$, Xu L, Yang T, Wang F. High-mobility group box-1 and its role in angiogenesis. J Leukoc Biol (2014) 95:563-74. doi:10.1189/jlb.0713412

70. Chavakis E, Hain A, Vinci M, Carmona G, Bianchi ME, Vajkoczy P, et al. High-mobility group box 1 activates integrin-dependent homing of endothelial progenitor cells. Circ Res (2007) 100:204-12. doi:10.1161/01. RES.0000257774.55970.f4

71. Mitola S, Belleri M, Urbinati C, Coltrini D, Sparatore B, Pedrazzi M, et al. Cutting edge: extracellular high mobility group box-1 protein is a proangiogenic cytokine. J Immunol (2006) 176:12-5. doi:10.4049/jimmunol.176.1.12

72. Van Beijnum JR, Nowak-Sliwinska P, van den Boezem E, Hautvast $P$, Buurman WA, Griffioen AW. Tumor angiogenesis is enforced by autocrine regulation of high-mobility group box 1. Oncogene (2013) 32:363-74. doi:10.1038/ onc.2012.49
73. Campana L, Santarella F, Esposito A, Maugeri N, Rigamonti E, Monno A, et al. Leukocyte HMGB1 is required for vessel remodeling in regenerating muscles. J Immunol (2014) 192:5257-64. doi:10.4049/jimmunol.1300938

74. Fang P, Pan H-C, Lin SL, Zhang W-Q, Rauvala H, Schachner M, et al. HMGB1 contributes to regeneration after spinal cord injury in adult zebrafish. Mol Neurobiol (2014) 49:472-83. doi:10.1007/s12035-013-8533-4

75. Dong Y, Gu Y, Huan Y, Wang Y, Liu Y, Liu M, et al. HMGB1 protein does not mediate the inflammatory response in spontaneous spinal cord regeneration: a hint for CNS regeneration. J Biol Chem (2013) 288:18204-18. doi:10.1074/ jbc.M113.463810

76. Straino S, Di Carlo A, Mangoni A, De Mori R, Guerra L, Maurelli R, et al. High-mobility group box 1 protein in human and murine skin: involvement in wound healing. J Invest Dermatol (2008) 128:1545-53. doi:10.1038/ sj.jid.5701212

77. Dardenne AD, Wulff BC, Wilgus TA. The alarmin HMGB-1 influences healing outcomes in fetal skin wounds. Wound Repair Regen (2013) 21:282-91. doi:10.1111/wrr.12028

78. Kitahara T, Takeishi Y, Harada M, Niizeki T, Suzuki S, Sasaki T, et al. Highmobility group box 1 restores cardiac function after myocardial infarction in transgenic mice. Cardiovasc Res (2008) 80:40-6. doi:10.1093/cvr/cvn163

79. Limana F, Germani A, Zacheo A, Kajstura J, Di Carlo A, Borsellino G, et al. Exogenous high-mobility group box 1 protein induces myocardial regeneration after infarction via enhanced cardiac C-kit+ cell proliferation and differentiation. Circ Res (2005) 97:e73-83. doi:10.1161/01. RES.0000186276.06104.04

80. Rossini A, Zacheo A, Mocini D, Totta P, Facchiano A, Castoldi R, et al. HMGB1-stimulated human primary cardiac fibroblasts exert a paracrine action on human and murine cardiac stem cells. J Mol Cell Cardiol (2008) 44:683-93. doi:10.1016/j.yjmcc.2008.01.009

81. Takahashi K, Fukushima S, Yamahara K, Yashiro K, Shintani Y, Coppen SR, et al. Modulated inflammation by injection of high-mobility group box 1 recovers post-infarction chronically failing heart. Circulation (2008) 118:S106-14. doi:10.1161/CIRCULATIONAHA.107.757443

82. Limana F, Esposito G, Fasanaro P, Foglio E, Arcelli D, Voellenkle C, et al. Transcriptional profiling of HMGB1-induced myocardial repair identifies a key role for Notch signaling. Mol Ther (2013) 21:1841-51. doi:10.1038/ $\mathrm{mt} .2013 .137$

83. Volz HC, Seidel C, Laohachewin D, Kaya Z, Müller OJ, Pleger ST, et al. HMGB1: the missing link between diabetes mellitus and heart failure. Basic Res Cardiol (2010) 105:805-20. doi:10.1007/s00395-010-0114-3

84. Kohno T, Anzai T, Naito K, Miyasho T, Okamoto M, Yokota H, et al. Role of high-mobility group box 1 protein in post-infarction healing process and left ventricular remodelling. Cardiovasc Res (2009) 81:565-73. doi:10.1093/cvr/ cvn291

85. Dormoy-Raclet V, Cammas A, Celona B, Lian XJ, van der Giessen K, Zivojnovic $\mathrm{M}$, et al. HuR and miR-1192 regulate myogenesis by modulating the translation of HMGB1 mRNA. Nat Commun (2013) 4:2388. doi:10.1038/ncomms3388

86. De Mori R, Straino S, Di Carlo A, Mangoni A, Pompilio G, Palumbo R, et al. Multiple effects of high mobility group box protein 1 in skeletal muscle regeneration. Arterioscler Thromb Vasc Biol (2007) 27:2377-83. doi:10.1161/ ATVBAHA.107.153429

87. Degryse B, Bonaldi T, Scaffidi P, Müller S, Resnati M, Sanvito F, et al. The high mobility group (HMG) boxes of the nuclear protein HMG1 induce chemotaxis and cytoskeleton reorganization in rat smooth muscle cells. J Cell Biol (2001) 152:1197-206. doi:10.1083/jcb.152.6.1197

88. Sorci G, Riuzzi F, Arcuri C, Giambanco I, Donato R. Amphoterin stimulates myogenesis and counteracts the antimyogenic factors basic fibroblast growth factor and S100B via RAGE binding. Mol Cell Biol (2004) 24:4880-94. doi:10.1128/MCB.24.11.4880-4894.2004

89. Palumbo R, Sampaolesi M, De Marchis F, Tonlorenzi R, Colombetti S, Mondino A, et al. Extracellular HMGB1, a signal of tissue damage, induces mesoangioblast migration and proliferation. J Cell Biol (2004) 164:441-9. doi:10.1083/jcb.200304135

90. Vitiello L, Gorini S, Rosano G, la Sala A. Immunoregulation through extracellular nucleotides. Blood (2012) 120:511-8. doi:10.1182/ blood-2012-01-406496

91. Yu N, Erb L, Shivaji R, Weisman GA, Seye CI. Binding of the P2Y2 nucleotide receptor to filamin A regulates migration of vascular smooth muscle cells. Circ Res (2008) 102:581-8. doi:10.1161/CIRCRESAHA.107.162271 
92. Albert JL, Boyle JP, Roberts JA, Challiss RA, Gubby SE, Boarder MR. Regulation of brain capillary endothelial cells by $\mathrm{P} 2 \mathrm{Y}$ receptors coupled to $\mathrm{Ca} 2+$, phospholipase $\mathrm{C}$ and mitogen-activated protein kinase. Br J Pharmacol (1997) 122:935-41. doi:10.1038/sj.bjp.0701453

93. Satterwhite CM, Farrelly AM, Bradley ME. Chemotactic, mitogenic, and angiogenic actions of UTP on vascular endothelial cells. Am J Physiol (1999) 276:H1091-7.

94. Jin H, Seo J, Eun SY, Joo YN, Park SW, Lee JH, et al. P2Y2 R activation by nucleotides promotes skin wound-healing process. Exp Dermatol (2014) 23:480-5. doi:10.1111/exd.12440

95. Erlinge D. Extracellular ATP: a growth factor for vascular smooth muscle cells. Gen Pharmacol (1998) 31:1-8. doi:10.1016/S0306-3623(97)00420-5

96. Nakagawa S, Omura T, Yonezawa A, Yano I, Nakagawa T, Matsubara K. Extracellular nucleotides from dying cells act as molecular signals to promote wound repair in renal tubular injury. Am J Physiol Renal Physiol (2014) 307:F1404-11. doi:10.1152/ajprenal.00196.2014

97. Gonzales E, Julien B, Serrière-Lanneau V, Nicou A, Doignon I, Lagoudakis $\mathrm{L}$, et al. ATP release after partial hepatectomy regulates liver regeneration in the rat. J Hepatol (2010) 52:54-62. doi:10.1016/j.jhep.2009.10.005

98. Herrgen L, Voss OP, Akerman CJ. Calcium-dependent neuroepithelial contractions expel damaged cells from the developing brain. Dev Cell (2014) 31:599-613. doi:10.1016/j.devcel.2014.10.012

99. Weihs AM, Fuchs C, Teuschl AH, Hartinger J, Slezak P, Mittermayr R, et al. Shock wave treatment enhances cell proliferation and improves wound healing by ATP release-coupled extracellular signal-regulated kinase (ERK) activation. J Biol Chem (2014) 289:27090-104. doi:10.1074/jbc.M114.580936

100. Taboubi S, Milanini J, Delamarre E, Parat F, Garrouste F, Pommier G, et al. G alpha(q/11)-coupled P2Y2 nucleotide receptor inhibits human keratinocyte spreading and migration. FASEBJ(2007) 21:4047-58. doi:10.1096/fj.06-7476com

101. Kaczmarek E, Erb L, Koziak K, Jarzyna R, Wink MR, Guckelberger O, et al. Modulation of endothelial cell migration by extracellular nucleotides: involvement of focal adhesion kinase and phosphatidylinositol 3-kinase-mediated pathways. Thromb Haemost (2005) 93:735-42. doi:10.1267/THRO0 5040735

102. Howard JD, Sarojini H, Wan R, Chien S. Rapid granulation tissue regeneration by intracellular ATP delivery - a comparison with Regranex. PLoS One (2014) 9:e91787. doi:10.1371/journal.pone.0091787

103. Takada H, Furuya K, Sokabe M. Mechanosensitive ATP release from hemichannels and $\mathrm{Ca}^{2+}$ influx through TRPC6 accelerate wound closure in keratinocytes. J Cell Sci (2014) 127:4159-71. doi:10.1242/jcs.147314
104. Gault WJ, Enyedi B, Niethammer P. Osmotic surveillance mediates rapid wound closure through nucleotide release. J Cell Biol (2014) 207:767-82. doi:10.1083/jcb.201408049

105. Higgins G, Buchanan P, Perriere M, Al-Alawi M, Costello RW, Verriere V, et al. Activation of P2RY11 and ATP release by lipoxin A4 restores the airway surface liquid layer and epithelial repair in cystic fibrosis. Am J Respir Cell Mol Biol (2014) 51:178-90. doi:10.1165/rcmb.2012-0424OC

106. Hill LM, Gavala ML, Lenertz LY, Bertics PJ. Extracellular ATP may contribute to tissue repair by rapidly stimulating purinergic receptor X7-dependent vascular endothelial growth factor release from primary human monocytes. J Immunol (2010) 185:3028-34. doi:10.4049/jimmunol.1001298

107. Mayo C, Ren R, Rich C, Stepp MA, Trinkaus-Randall V. Regulation by P2X7: epithelial migration and stromal organization in the cornea. Invest Ophthalmol Vis Sci (2008) 49:4384-91. doi:10.1167/iovs.08-1688

108. MacLeod AS, Rudolph R, Corriden R, Ye I, Garijo O, Havran WL. Skin-resident $\mathrm{T}$ cells sense ultraviolet radiation-induced injury and contribute to DNA repair. J Immunol (2014) 192:5695-702. doi:10.4049/ jimmunol.1303297

109. Jacob F. La Logique du vivant. Une histoire de l'hérédité. Paris: Editions Gallimard - coll. Tel (1970).

110. Chen GY, Nuñez G. Sterile inflammation: sensing and reacting to damage. Nat Rev Immunol (2010) 10:826-37. doi:10.1038/nri2873

111. Carta S, Castellani P, Delfino L, Tassi S, Venè R, Rubartelli A. DAMPs and inflammatory processes: the role of redox in the different outcomes. J Leukoc Biol (2009) 86:549-55. doi:10.1189/jlb.1008598

112. Ghesquière B, Wong BW, Kuchnio A, Carmeliet P. Metabolism of stromal and immune cells in health and disease. Nature (2014) 511:167-76. doi:10.1038/ nature 13312

Conflict of Interest Statement: The authors have no conflicting financial interests. However, Marco Emilio Bianchi is founder and part owner of HMGBiotech, a company that provides goods and services related to HMGB proteins, and Emilie Vénéreau was partially supported by HMGBiotech.

Copyright (c) 2015 Vénéreau, Ceriotti and Bianchi. This is an open-access article distributed under the terms of the Creative Commons Attribution License (CC BY). The use, distribution or reproduction in other forums is permitted, provided the original author(s) or licensor are credited and that the original publication in this journal is cited, in accordance with accepted academic practice. No use, distribution or reproduction is permitted which does not comply with these terms. 